\title{
Photoinduced Ionic Polymerization. VI. Molecular Weight Distribution in Cationic Polymerization of $\alpha$-Methylstyrene
}

\author{
Yukio Yamamoto, Masahiro IrIE, and Koichiro Hayashi \\ The Institute of Scientific and Industrial Research, Osaka University, \\ Yamadakami, Suita 565, Japan.
}

(Received March 25, 1976)

\begin{abstract}
The photoinduced cationic polymerization of $\alpha$-methylstyrene was carried out in dichloromethane solution using pyromellitic dianhydride as an electron acceptor, and the molecular weight distributions of the resulting polymer were measured by gel-permeation chromatography. It was found that the molecular weight distribution was bimodal at low monomer concentration and low temperature. The lower molecular weight peak, which increased with decreasing monomer concentration and temperature, was assigned to the free-ion polymerization, and the higher-molecular weight one to the ion-pair polymerization. It was shown that the molecular weight of the polymer produced by the free-ion polymerization decreased with decreasing monomer concentration, but was not affected by temperature, while that of the polymer produced by the ion-pair polymerization decreased with increasing temperature, but'was not affected by the monomer concentration. The propagation mechanism was discussed in connection with the conventional catalytic and radiation-induced polymerizatson.
\end{abstract}

KEY WORDS Photoinduced Polymerization / Charge-Transfer

Complex / $\alpha$-Methylstyrene / Cationic Polymerization / Molecular

Weight Distribution /

In our previous papers it has been shown that polymerization occurred when $\alpha$-methylstyrene was illuminated in the presence of an electron acceptor, such as tetracyanobenzene or pyromellitic dianhydride (PMDA), in chlorinated hydrocarbon solutions under extensively dried conditions. $^{1-3}$ Physicochemical studies revealed that the polymerization is initiated by the monomer radical-cation produced through the dissociation of a photoexcited charge-transfer complex of the monomer and the electron acceptor. $^{1-6}$ Furthermore, studies on the electrical conductivity of the polymerization system suggested that both free ions and ion pairs contribute to the polymerization..$^{4-6}$.

The process of the polymerization is expressed by the following scheme, as previously reported

$$
\begin{aligned}
& D+A \rightleftarrows(D \cdot A) \stackrel{h \nu}{\rightarrow}(D \cdot A)^{*} \\
& \left.\rightarrow \underset{\downarrow}{\left(D_{\text {solv }}^{+} \cdots A_{\text {solv }}^{-}\right.}\right) \underset{\substack{\downarrow \\
\text { polymer }}}{D_{\text {solv }}^{+}}+A_{\text {solv }}^{-}
\end{aligned}
$$

where $D_{\text {solv }}^{+}$and $A_{\text {solv }}^{-}$denote the solvated radical-ions of the electron donor, $\alpha$-methylstyrene, and acceptor, PMDA or tetracyanobenzene, respectively.

The contributions of free ions and ion pairs to the propagation have already been confirmed in the case of the anionic polymerization of styrene. Studies have also been done on the propagating species of the cationic polymerization of styrene, and the presence of free ions and ion pairs has been suggested by bimodal molecular weight distributions of the polymers produced by perchloric acid ${ }^{7}$ and acetyl perchlorate..$^{8,9}$

Thus, it is of interest to elucidate the propagation mechanism, especially the effect of the anion, in the photoinduced cationic polymerization of $\alpha$-methylstyrene. In the present study the molecular weight distribution (MWD) of the polymer produced by the illumination of the complex of $\alpha$-methylstyrene with PMDA in dichloromethane solution was measured in order to obtain information about the propagating species. The propagation mechanism was discussed in connection with that of the conventional catalyst- and radiation-induced cationic 
polymerizations.

\section{EXPERIMENTAL}

The experimental procedures were the same as those reported previously. ${ }^{1}$ The polymerization was conducted at various monomer concentrations $\left(m_{0}\right)$ from 0.57 to $2.0 \mathrm{~mol} / l$ in dichloromethane and at temperatures from -74 to $4{ }^{\circ} \mathrm{C}$ in the presence of about $1 \times 10^{-3} \mathrm{~mol} / \mathrm{l}$ of PMDA. The illumination was carried out with a super high pressure mercury lamp; the excitation was limited to the charge-transfer band, which is around $360 \mathrm{~nm}$, by the use of a color filter (Toshiba UV35) transmitting above $350 \mathrm{~nm}$. The MWD was measured by gel-peremation chromatography (Toyo Soda HLC 801).

\section{RESULTS AND DISCUSSION}

The MWD was significantly affected by the monomer concentration and the polymerization temperature. MWD was bimodal at low monomer concentration and low temperature, which indicates that the two chain ends with different reactivities propagate independently.

Figure 1 shows the MWD's of the polymers produced at various monomer concentrations at $-74^{\circ} \mathrm{C}$. The MWD is clearly bimodal when $m_{0}<1.3 \mathrm{~mol} / l$. The peak of lower molecular weight increased in relative size and shifted to larger elution volumes as the monomer concentration was decreased. On the other hand, the position of the higher molecular weight peak was not affected by the monomer concentration.

The temperature dependence of the MWD was examined at $m_{0}=0.57 \mathrm{~mol} / l$ (Figure 2). The MWD was bimodal below $-50^{\circ} \mathrm{C}$, and the proportion of the lower molecular weight peak decreased with the increase in temperature, resulting in the monomodal distribution at higher temperatures. The dependence of the position of the two peaks on the temperature was in contrast to that on the monomer concentration; the higher molecular weight peak shifted to larger elution volumes with increasing temperature, while the lower one had an almost constant elution volume. The MWD was apparently monomodal at higher temperatures, -30 and $4^{\circ} \mathrm{C}$.
The dependence of the MWD on conversion was studied at $m_{0}=0.57 \mathrm{~mol} / l$ and at $-74^{\circ} \mathrm{C}$. It was found that the bimodal MWD was slightly affected by the conversion; the relative height of the higher molecular weight peak increased with the increase in conversion, from 0.4 at $12 \%$ to 0.5 at $46 \%$. However, such an effect on the MWD was much smaller than that of the monomer concentration and temperature in the range of the conversion in the present study. On the other hand, the positions of two peaks did not vary with conversion.

The two propagating species which give the bimodal MWD shown in Figures 1 and 2 are concluded to be free-ions and ion pairs from the results of the previous studies: (a) The

(a)

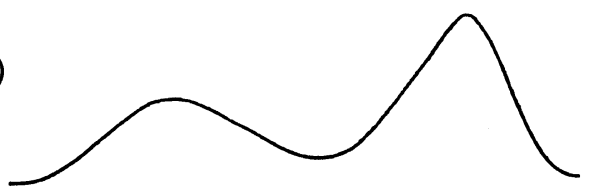

(b)
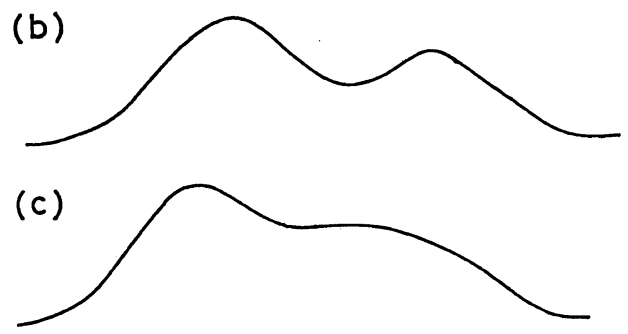

(d)

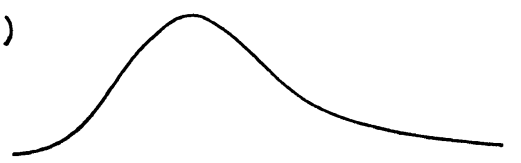

(e)

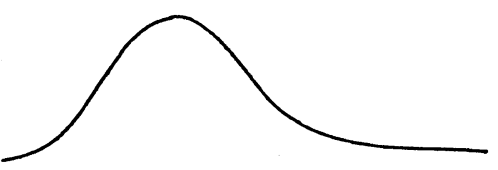

Molecular Weight

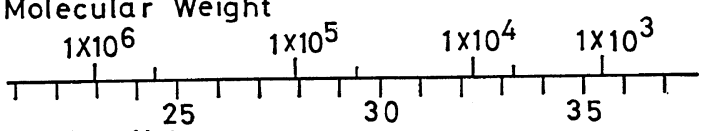

Elution Volume

Figure 1. Molecular weight distributions of poly$\left(\alpha\right.$-methylstyrene)s produced at $-74^{\circ} \mathrm{C}$ and various monomer concentrations. The monomer concentrations and convertions are: (a) $0.57 \mathrm{~mol} / l, 46 \%$; (b) $0.69 \mathrm{~mol} / l, 43 \%$; (c) $0.97 \mathrm{~mol} / l, 31 \%$; (d) 1.3 $\mathrm{mol} / l, 7 \%$; (e) $2.0 \mathrm{~mol} / l, 11 \%$. 
(a)

(b)

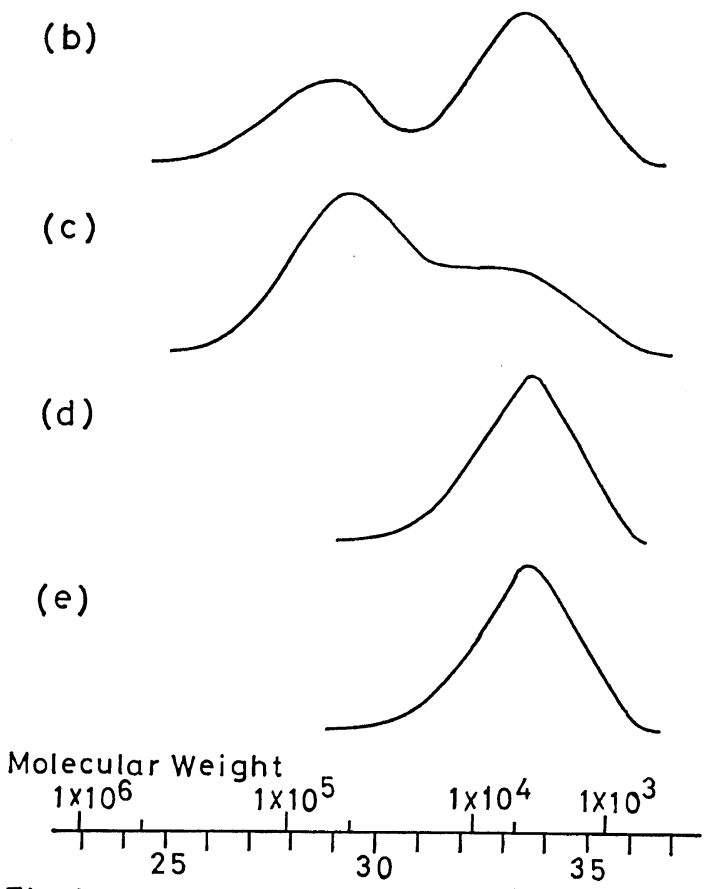

Elution Volume

Figure 2. Molecular weight distributions of poly$(\alpha$-methylstyrene)s produced at the monomer concentration of $0.57 \mathrm{~mol} / l$ and various temperatures. Temperatures and conversions are: (a) $-74^{\circ} \mathrm{C}$, $46 \%$; (b) $-60^{\circ} \mathrm{C}, 52 \%$; (c) $-50^{\circ} \mathrm{C}, 35 \%$; (d) $-30^{\circ} \mathrm{C}$, $29 \%$; (e) $4{ }^{\circ} \mathrm{C}, 12 \%$.

propagating species involved in the photoinduced polymerization of $\alpha$-methylstyrene are only cationic ones; the coexistence of the propagation by other species, an anion or a radical, can be ruled out. ${ }^{1-3}$ (b) The photocurrent was observed in the polymerization system, indicating that the ion pair formed from the excited charge-transfer complex dissociates into free-ions. ${ }^{4-6}$ (c) The dependence of the rate of polymerization on light intensity indicates the coexistence of freeion and ion-pair polymerizations; the power dependences of the rates of polymerization on light intensity for the free-ion and ion-pair polymerizations are 0.5 and 1.0, respectively, and are between 0.5 and 1.0 in the photoinduced poly- merization of $\alpha$-methylsryrene. ${ }^{10}$

It has recently been reported that in the polymerizations of styrene by perchloric acid and acetyl perchlorate the polymers possess bimodal MWD's; this suggests the contributions of two propagating species, free ions and ion pairs. Another type of propagating species, an ester, has been proposed by Plesch for the polymerization of styrene by perchloric acid. ${ }^{11}$ However, in the photoinduced cationic polymerization of $\alpha$-methylstyrene it is unlikely that an ester is produced from the propagating cation and the PMDA radical-anion, and the contribution of such a type of propagating species can be ruled out.

On the basis of the facts that the lower the monomer concentration and the temperature, the larger is the polarity of the solution, and that an ion pair tends to dissociate more to free ions at larger polarity, it seems reasonable to conclude that the lower polymers, whose population increased, are formed by the free-ion polymerization. Consequently, the higher polymers should have been formed by the ion-pair polymerization. It was confirmed that the photocurrent in the polymerization system increases with decreasing temperature and monomer concentration. ${ }^{10}$ Furthermore, the power dependence of the rate of polymerization on light intensity decreased with decreasing the temperature and the monomer concentration from $1.0\left(-15^{\circ} \mathrm{C}, 1.9 \mathrm{~mol} / l\right)$ to 0.67 $\left(-74^{\circ} \mathrm{C}, 0.53 \mathrm{~mol} / \mathrm{l}\right) .{ }^{10}$ These results indicate that the contribution of the free-ion polymerization increases with decreasing the temperature and the monomer concentration, and support the above assignment.

The rate of polymerization increased when the monomer concentration and temperature were lowered. This result is attributable to the facts that an increase in polarity of the solution results in a higher extent of the dissociation of ion pairs to free ions and that the rate of the propagation of free ions is greater than that of ion pairs.

The $\bar{M}_{n}$ and $\bar{M}_{w} / \bar{M}_{n}$ values of the polymers are summarized in Table I. The corresponding values for the individual peaks of the bimodal MWD are also shown in the table, though there is some uncertainty in these values when the two peaks overlap appreciably. 
Table I. Molecular weight of poly ( $\alpha$-methylstyrene)

\begin{tabular}{ccll}
\hline $\begin{array}{c}\text { Tempera- } \\
\text { ture, } \\
{ }^{\circ} \mathrm{C}\end{array}$ & $\begin{array}{c}\text { Monomer } \\
\text { concentration, } \\
\text { mol } / l\end{array}$ & \multicolumn{1}{c}{$\bar{M}_{n}^{\mathrm{a}}$} & $\bar{M}_{w / M_{n}}{ }^{\mathrm{a}}$ \\
\hline-74 & 2.0 & $6.6 \times 10^{4}$ & 2.9 \\
-74 & 1.3 & $7.0 \times 10^{4}$ & 3.0 \\
-74 & 0.97 & $4.0 \times 10^{4}$ & 5.7 \\
& & $1.8 \times 10^{5}(\mathrm{H})$ & $1.9(\mathrm{H})$ \\
& & $1.7 \times 10^{4}(\mathrm{~L})$ & $2.1(\mathrm{~L})$ \\
-74 & 0.69 & $2.9 \times 10^{4}$ & 6.3 \\
& & $1.5 \times 10^{5}(\mathrm{H})$ & $1.4(\mathrm{H})$ \\
& & $1.1 \times 10^{4}(\mathrm{~L})$ & $1.9(\mathrm{~L})$ \\
-74 & 0.57 & $5.9 \times 10^{3}$ & 17 \\
& & $1.3 \times 10^{5}(\mathrm{H})$ & $1.5(\mathrm{H})$ \\
& & $3.5 \times 10^{3}(\mathrm{~L})$ & $1.8(\mathrm{~L})$ \\
-60 & 0.57 & $5.9 \times 10^{3}$ & 7.0 \\
& & $8.1 \times 10^{4}(\mathrm{H})$ & $1.3(\mathrm{H})$ \\
& & $3.9 \times 10^{3}(\mathrm{~L})$ & $1.9(\mathrm{~L})$ \\
-50 & 0.57 & $1.0 \times 10^{4}$ & 4.9 \\
& & $3.9 \times 10^{4}(\mathrm{H})$ & $1.8(\mathrm{H})$ \\
& & $3.6 \times 10^{3}(\mathrm{~L})$ & $2.2(\mathrm{~L})$ \\
-30 & 0.57 & $3.6 \times 10^{3}$ & 2.0 \\
4 & 0.57 & $3.5 \times 10^{3}$ & 2.0 \\
4 & 2.0 & $3.5 \times 10^{3}$ & 1.7 \\
\hline
\end{tabular}

a (H) anp (L) show the values of the higher and lower molecular weight peaks, respectively, of the bimodal distribution.

The results shown in Figures 1 and 2 indicate that the two propagating species yield polymers of similar molecular weights at higher monomer concentrations or at higher temperatures (Figures 1 and 2). The $\bar{M}_{w} / \bar{M}_{n}$ value will serve to indicate whether or not the free-ion and ion-pair polymerizations coexist when the MWD is unimodal. The $\bar{M}_{w} / \bar{M}_{n}$ values were 3.0 and 2.9 when $m_{0}=1.3$ and 2.0 , respectively, at $-74^{\circ} \mathrm{C}$ (Table 1). These large values suggest that the free-ion polymerization also contributes to some extent even at these higher monomer concentrations.

Dependence of the Molecular Weight on the Monomer Concentration and Temperature

Ion-Pair Polymerization. As is shown in Table I, the molecular weights of the polymers produced with $m_{0}=0.57$ and $2.0 \mathrm{~mol} / l$ at $4^{\circ} \mathrm{C}$ were the same (3500); it can be considered that under these conditions the ion-pair polymerization is dominant. The results in Figure 1 also indicate that the molecular weight of the polymer produced by the ion-pair polymerization is not much

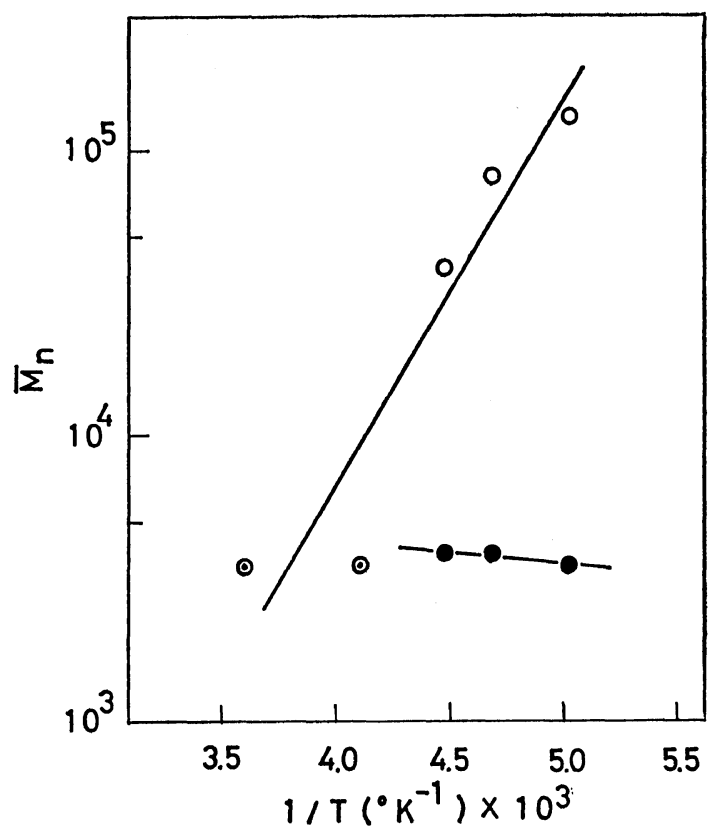

Figure 3. Temperature dependence of molecular weight of $\operatorname{poly}(\alpha$-methylstyrene)s produced at the monomer concentration of $0.57 \mathrm{~mol} / l: \quad \bigcirc$, the higher molecular weight peak; $\bullet$, the lower molecular weight peak; $\odot$, the monomodal peaks at -30 and $4^{\circ} \mathrm{C}$.

affected by the monomer concentration, and that the degree of polymerization is governed by $k_{p} / k_{t m}\left(k_{p}\right.$ and $k_{t m}$ denote the rate constants of propagation and monomer transfer, respectively).

The plot of the molecular weight of the polymer produced at $m_{0}=0.57 \mathrm{~mol} / l$ against the reciprocal of temperature is shown in Figure 3, where the values of the individual peaks are plotted for the bimodal distributions. From the plot of the higher molecular weight peaks the activation energy of molecular weight of the ion-pair polymerization was obtained to be -6.2 $\mathrm{kcal} / \mathrm{mol}$, which corresponds to the difference in the activation energies between the propagation and the monomer transfer reactions. In the conventional catalytic polymerization of this monomer the molecular weight increases with decreasing temperature, ${ }^{12-14}$ and the difference in activation energy between the propagation and the monomer transfer is $-9.5 \mathrm{kcal} / \mathrm{mol}$ for the polymerization in dichloromethane by boron 
trifluoride etherate. The value obtained in the photoinduced ion-pair polymerization is comparable to that of the catalytic polymerization. The small difference is considered to be due to the effect of the anions, as reported in the case of styrene. ${ }^{15}$

Free-Ion Polymerization. As is shown in Figures 1 and 3 , the molecular weight of the polymer produced by the free-ion polymerization increases with increasing monomer concentration, but is not appreciably affected by temperature.

In this connection, the $\gamma$ ray-induced polymerization of this monomer, where the free-ion polymerization occurs, was examined in dichloromethane solution. The molecular weight of the polymer increased with increasing monomer concentration from $4.8 \times 10^{3}$ at $2.7 \mathrm{~mol} / \mathrm{l}$ to $2.6 \times$ $10^{4}$ in bulk at $0^{\circ} \mathrm{C}$, and was not appreciably affected by temperature.

Such dependences of the molecular weight on the monomer concentration and temperature are similar to those observed in the photoinduced free-ion polymerization, and such a result confirms the assignment of the lower molecular weight peak to the free-ion polymerization.

\section{REFERENCES}

1. M. Irie, S. Tomimoto, and K. Hayashi, $J$. Polym. Sci., Part B, 8, 585 (1970).
2. M. Irie, S. Tomimoto, and K. Hayashi, ibid., Part A-1, 10, 3235 (1972).

3. M. Irie, S. Tomimoto, and K. Hayashi, ibid., Part A-1, 10, 3243 (1972).

4. M. Irie, S. Tomimoto, and K. Hayashi, $J$. Phys. Chem., 76, 1419 (1972).

5. Ka. Hayashi, M. Irie, and K. Hayashi, Polymer J., 3, 762 (1972).

6. M. Irie, H. Masuhara, K. Hayashi, and N. Mataga, J. Phys. Chem., 78, 341 (1974).

7. D. C. Pepper, Makromol. Chem. 175, 1077 (1974).

8. T. Masuda and T. Higashimura, J. Polym. Sci., Part B, 9, 783 (1971).

9. T. Higashimura and O. Kishiro, J. Polym. Sci. Polym. Chem. Ed., 12, 967 (1974).

10. M. Irie and K. Hayashi, Abstructs, 22nd Polymer Symposium of the Society of Polymer Science, Japan, 1973, S7A07.

11. P. H. Plesch, Adv. Polym. Sci., 8, 137 (1971); D. J. Dunn, E. Mathias, and P. H. Plesch, Europ. Polym. J., 12, 1 (1976), and the references cited there.

12. A. B. Hersberger, J. C. Reid, and R. G. Heiligmann, Ind. Eng. Chem., 37, 1073 (1945).

13. R. G. Heiligmann, J. Polym. Sci., 6, 155 (1951).

14. Y. Imanishi, T. Higashimura, and S. Okamura, Kobunshi Kagaku (Chem. High Polymers), 17, 236 (1960).

15. A. R. Mathieson in "The Chemistry of Cationic Polymerization", P. H. Plesch, Ed., Pergamon Press, Oxford, 1963, p 235. 